\title{
Traumatic Splenic Injuries in Khartoum, Sudan
}

\author{
Isameldin O. Ibrahim ${ }^{1}$, Aamir A. Hamza ${ }^{2 *}$, M. E. Ahmed ${ }^{3}$ \\ ${ }^{1}$ Department of Surgery, Omdurman Teaching Hospital, Khartoum, Sudan \\ ${ }^{2}$ Department of Surgery, College of Medicine and Health Sciences, Bahri University, Khartoum, Sudan \\ ${ }^{3}$ Department of General Surgery, Faculty of Medicine, Khartoum University, Khartoum, Sudan \\ Email: ${ }^{2}$ aamirhamzza@yahoo.co.uk
}

Received October 28, 2013; revised November 20, 2013; accepted November 27, 2013

Copyright (c) 2013 Isameldin O. Ibrahim et al. This is an open access article distributed under the Creative Commons Attribution License, which permits unrestricted use, distribution, and reproduction in any medium, provided the original work is properly cited. In accordance of the Creative Commons Attribution License all Copyrights @ 2013 are reserved for SCIRP and the owner of the intellectual property Isameldin O. Ibrahim et al. All Copyright (C 2013 are guarded by law and by SCIRP as a guardian.

\begin{abstract}
Background: Spleen injuries are most commonly associated with blunt abdominal trauma and represent a potentially life-threatening condition. Objectives: To study the pattern of splenic injuries of the patient, management instituted and its outcome at Khartoum. Patients and Methods: This is a prospective, analytic and hospital-based multicenteric study, conducted at the three main Teaching hospitals at Khartoum. The study was carried over a period from April 2012 to February 2013. It includes all patients, diagnosed as traumatic splenic injury. Excluded were patients with history of splenic disease, iatrogenic injury or spontaneous rupture. Results: The study included 47 patients: their mean age was 26.4 years $(S D \pm 14.5)$. Most of them $41(87.2 \%)$ were in the first four decades of life. Males were predominant 41 (87.2\%), with a male to female ratio of 6.8:1. The majority of our patients had blunt abdominal trauma 39 (83\%), of whom, road traffic accident accounted for $51.1 \%$ and none reported cases of gunshot. Isolated splenic injury was found in 23 (48.9\%), and Haemodynamic stability was seen in 27 (57.4\%) on presentation. The initial haemoglobin assessment revealed $<9$ gram/dl in 53.2\%. CT scan was performed to 24 (51.1\%), of whom 66 patients were Grade I and II and none of our patients were diagnosed as Grade V. Blood transfusion was required in 42 (89.4\%). Operative treatment was adopted in 66\% (61.7\% total splenectomy and 4.3\% splenorrhaphy), while selective non-operative management was successful in 16 (34\%) of the patients. Higher intra-operative grade of splenic injury was found to be significantly associated with blunt abdominal trauma, haemodynamic instability and associated intra-abdominal injuries. 44 patients (93.6\%) were discharged home in a general good condition. The morbidity and mortality were seen in $8.5 \%$ and $6.4 \%$ respectively. Conclusion: Splenic injuries usually follow blunt abdominal trauma, particularly after road traffic accidents. It is common during the first four decades of life with males being frequently affected. The great success rate of adopting selective non-operative management is worthwhile.
\end{abstract}

Keywords: Blunt Splenic Trauma; Nonoperative Management; Splenectomy; Splenic Injury

\section{Introduction}

The incidence of splenic injury in poly trauma patients was reported to be $44 \%$ and combined splenic and hepatic lesions in (18\%) [1]. Splenic injuries represent approximately $25 \%$ of all blunt injuries to the abdominal viscera. Penetrating injuries also frequently involve the spleen along with other abdominal organs [2]. The recent trend in management of splenic trauma is preservation whenever possible. This can be non-operative or operative splenorrhaphy [3]. This follows the evolution in treatment of traumatic injuries of liver and spleen from

\footnotetext{
${ }^{*}$ Corresponding author.
}

aggressive to damage control surgery to non-operative [4]. Trends in management have changed over the years. Traditionally, laparotomy and splenectomy were the standard management. Presently, selective non-operative management (SNOM) of splenic injury is the most common management strategy in haemodynamically stable patient $[5,6]$. Laparoscopic splenectomy was successfully carried out for the first time in colonoscopic grade IV splenic injury [7]. Patients who are haemodynamically stable can be safely treated with SNOM [8,9]. The splenic arterial embolization in haemodynamically stable patients has been attributed to the relatively high failure rate of such a treatment $(10 \%-31 \%)$, with a re- 
sultant need for secondary splenectomy, and to the potential of missing other intra-abdominal injuries that require laparotomy [9].

\section{Patients and Methods}

This is a prospective, observational and analytic study. It is a hospital based, Multicenteric, conducted at the three main Teaching hospitals at Khartoum "Omdurman, Khartoum and Khartoum North”. The study was carried over a period extending from April 2012 to February 2013. It includes all patients, diagnosed as traumatic splenic injury by clinical assessment, investigations, or surgery. Excluded were patients with history of splenic disease, injury due to surgery or spontaneous rupture. Consecutive non probability sampling was adopted. Data were collected using, questionnaire. The variables include personal data, presenting features, blood and radiological investigations, treatment, operative findings and post-operative complications. Patient's informed consent was obtained, together with ethical clearance. Statistical analysis methods used were frequencies and 95\% confidence intervals (CI) for categorical data, mean, standard deviation, frequencies and compared the data, using Student's $t$-test and Chi-square tests when appropriate with significance taken at $\mathrm{P}$ value $<0.05$.

\section{Results}

The study included 47 patients, their mean age was 26.4 years (SD \pm 14.5$)$ and ranging from 2 to 65 years. Most of them 41 (87.2\%) were in the first four decades of life. One third was in the age group 21 - 30 years Table 1.

Males were predominant 41 (87.2\%), with a male to female ratio of 6.8:1. The majority of our patients had blunt abdominal trauma 39 (83\%), the rest 8 (17\%) were resulted from penetrating injuries. Road traffic accident , fall off a height, falling object and other assault accounted for $51.1 \% 19.1 \%$, $8.5 \%$ and $4.3 \%$ respectively, Table 2. Worth mentioning all penetrating cases were knives stab and no reported cases of gunshot, shotgun or impalement in this study. Only five patients (10.6\%)

Table 1. Age distribution in the study population $(n=47)$.

\begin{tabular}{cc}
\hline Age (years) & Frequency (\%) \\
\hline $0-10$ & $08(17.0)$ \\
$11-20$ & $90(19.1)$ \\
$21-30$ & $14(29.8)$ \\
$31-40$ & $10(21.3)$ \\
$41-50$ & $30(6.4)$ \\
$51-60$ & $01(2.1)$ \\
$>60$ & $20(4.3)$ \\
Total & $47(100)$ \\
\hline
\end{tabular}

presented to the surgical casualty within the first hour, more the half between 1 - 6 hours and 36.6\% after six hours.

Trauma does not respect any system, it involved the abdominal only in 23 (48.9\%), whereas that associated with chest injury in 11 (23.4), head and neck 9 (19.1\%) and extremities 4 (8.5\%) respectively. With respect to the associated intra-abdominal injuries, in the vast majority of our patients, isolated splenic injury was found to be involved in 33 (70\%) of the occasions and other organs were affected to lesser extend Table 3. Haemodynamic stability was seen in 27 (57.4\%) on presentation, the rest were shocked. The initial haemoglobin assessment revealed $<9 \mathrm{gram} / \mathrm{dl}$ in $53.2 \%$, and $>9$ gram $/ \mathrm{dl}$ in $46.8 \%$ of our patients.

CT scan was performed to 24 (51.1\%) and Focused Abdominal Sonography for Trauma (FAST) to 5 (10.6\%) of the patients. Grade I and II were seen equally by the CT scan in 33.3\% each, whereas Grade III and Grade IV were seen in $12.5 \%$ and $20.8 \%$ respectively and none of our patients was diagnosed as Grade V by the scan.

Blood transfusion was required in 42 (89.4\%) and 16 (34\%) patients received more than four pints of blood, 15 (31.9\%) received 1 - 2 pints, 11 (23.4\%) received 3 - 4 pints and only 5 patients needed no blood transfusion.

Operative treatment was adopted in $66 \%$ (61.7\% total splenectomy and $4.3 \%$ Splenorrhaphy), while 'SNOM' in 16 (34\%) of the patients. In the latter group initially they were 19 patients however the conservative measures

Table 2. Mode of trauma causing splenic injury.

\begin{tabular}{ccc}
\hline Mode of trauma & Frequency & Percent \\
\hline Road traffic accident & 24 & $51.1 \%$ \\
Fall off a height & 09 & $19.1 \%$ \\
Stab wound & 08 & $17.0 \%$ \\
Gunshot & 00 & $0.00 \%$ \\
Others & 06 & $12.8 \%$ \\
Total & 47 & 100 \\
\hline
\end{tabular}

Table 3. Associated intra-abdominal injuries.

\begin{tabular}{ccc}
\hline Organ injured & Frequency & Percent \\
\hline Spleen only & 33 & $70.2 \%$ \\
Small bowel \& mesentery & 05 & $10.6 \%$ \\
Stomach & 04 & $8.5 \%$ \\
Large bowel & 02 & $04.3 \%$ \\
Liver & 01 & $02.1 \%$ \\
Kidney & 01 & $02.1 \%$ \\
Others & 01 & $02.1 \%$ \\
Total & 47 & 100 \\
\hline
\end{tabular}


were successful in $84.2 \%$ of them and three patients were operated. These converted patients were all initially haemodynamically stable, and on laparotomy no associated intra-abdominal injuries were found but the splenic trauma was grade IV in two patients and grade III in the third one. Fortunately three of the shocked patients were treated non-operatively after stabilization; two of them had associated chest injuries and the third with head and neck injury.

The amount of haemoperotenium in the operated group, was found to be $<500 \mathrm{ml}$ in 4 (12.9\%), 500 - 1000 $\mathrm{ml}$ in 13 (41.9\%) and $>1000 \mathrm{ml}$ in 14 (45.2\%), Figure 1.

Higher intra-operative grade of splenic injury was found to be significantly associated with; blunt abdominal trauma, haemodynamic instability on presentation, need for blood transfusion, presence of large amount of haemoperotenium and associated intra-abdominal injuries Table 4.

Post-operatively 7 (14.9\%) were admitted to the Intensive Care Unit "ICU”, 5 (10.6\%) to the High Dependency Unit "HDU” and the rest to the general ward. Forty four patients (93.6\%) were discharged home in good general condition

\section{Morbidity and Mortality}

The morbidity in our study occurred in four patients (8.5\%), two cases of minor surgical site infection, one developed over-whelming post splenectomy sepsis
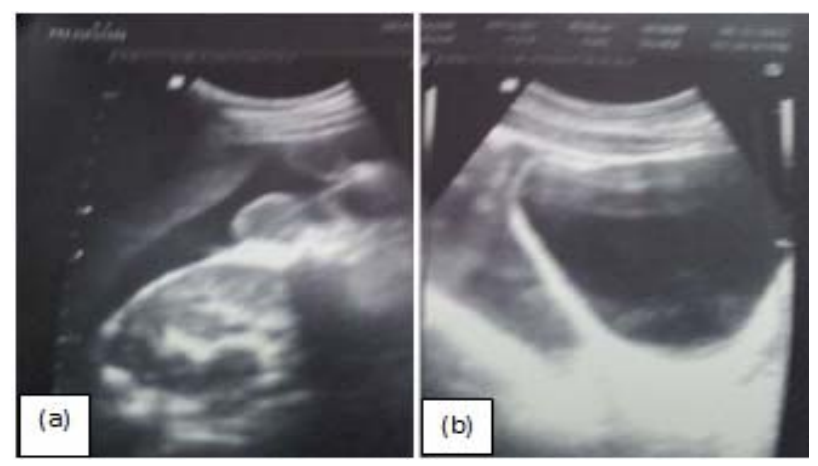

Figure 1. Fluid (Blood) detected by FAST in splenic injury. (a) In Morison's pouch. (b) In the pelvis (Rectovesicular space).

Table 4. Factors predicting higher grade of splenic injuries.

\begin{tabular}{cc}
\hline Factor & P value \\
\hline Blunt trauma & 0.002 \\
Haemodynamic instability & 0.023 \\
Need for blood transfusion & 0.036 \\
Presence of haemoperotenium & 0.000 \\
Associated abdominal injuries & 0.002 \\
\hline
\end{tabular}

(OPSS) and one had mesenteric vascular occlusion. There are three deaths (6.4\%) in this study. All received operative management, two after fail conservation. Associated extra-abdominal injuries were found in two of them (left haemothorax/massive intracranial bleeding). The length of hospital stay in our series varies between one week in (25\%) to three weeks in $(17 \%)$ and the rest $57 \%$ between one and three weeks.

\section{Discussion}

The mean age of 26.4 years ( $S D \pm 14.5$ ) in our study was found to be consistence with the reported age in another study done in Nigeria, mean of $24.2 \pm 15.2$ years [10]. However it was lower than $38 \pm 16$ (SD) years [11] and 32 years [6].

The male's gender constitutes the great majority $78.2 \%$ in our study. This was found to be similar to the reported in the literature $63 \%[12,13]$ and $76 \%$ [6], however our males where seven times the females number 6.8:1, which was higher compared to 3.9:1 [11], 2.2:1 [10], and 1.9:1 [14]. This can be explained by the fact males were breadwinners and the increase road traffic in the capital.

\subsection{Mode of Trauma in Splenic Injury}

Blunt abdominal trauma was the commonest cause of splenic injury in our study (83\%). This is comparable to the reported mode of trauma in other studies which range from $78 \%$ to $100 \%[5,10,12,13,15]$. Motorcycle accidents, assaults, fall from height, and sports, were the varieties causing blunt splenic injuries [15]. Jason J. Hallman, et al., on their study of 338 splenic trauma as an adverse effect of torso-protecting side airbags, occupants involved in left-side impacts without SAB, sustained injuries to their abdomen in $8.2 \%$ [16]. In our study, road traffic accidents were the reason in half the patients. This is similar to other studies, 42.9\% [12], 57\% [11], however, it is lower than $75.3 \%$ [10], 78\% [13], 84\% [6] and 91\% [14] in other series. Falling off a height rank second in our study as a cause of blunt splenic injury which is comparable to $[5,10]$. Our third cause was assaults and none of our patients inflicted sport injuries. All penetrating splenic injuries we received were cases of knives stab and no reported cases of gunshot. This contrasts the finding in Los Angeles, California were gunshot accounted for $70.4 \%$ of penetrating injuries to the spleen [17], this discrepancy might be attributed to variations in cultural context of the different communities, as knives were being carried by some of Sudanese tribes as part of their traditional heritage and self-defense weapon.

Haemodynamic instability was defined by a systolic blood pressure of less than $90 \mathrm{~mm} \mathrm{Hg}$ refractory to resuscitation maneuvers [11]. It was one of the presenting 
features of our patients and seen in $42.6 \%$. This contrast the reported $6.6 \%$ in the literature [17] and possibly the paucity of efficient ambulance system with it is trained emergency medical personnel's is a contributory factor.

\subsection{Scanning}

The primary goal of splenic ultrasonography in the setting of blunt abdominal trauma is to detect the presence of blood in the left upper quadrant [2]. FAST is used in haemodynamic stable patients, takes 2 min, has no role in grading with a sensitivity of $90 \%$ [5] and it replace diagnostic peritoneal lavage (DPL). It had been done to only five of our patients (10\%), none availability of the ultrasound in the emergency room or untrained surgical residents may be responsible for this low percentage of performance.

FAST detecting haemoperitoneum should lead to a CT scan for further evaluation of the nature and extent of injury [5]. CT scan is the modality used at most institutions. It provides the best evaluation of the spleen and the surrounding tissues. It images all of the abdominal organs simultaneously to exclude secondary injury [2]. It was been performed to half of our patients and revealed grade III and IV in 33.3\%, though these high grades of splenic injuries were diagnosed in $73 \%$ in Clay et al., study [18].

\subsection{Selective Non-Operative Management}

The initial choice of surgical versus nonsurgical management remains controversial [9]. Observational management involves admission to a unit with monitoring of vital signs, strict bed rest, frequent monitoring of red blood cell count, and serial abdominal examinations [5]. The American College of Surgeons' National Trauma Data Bank (NTDB 4.0) analyzed 35,767 splenic injuries. There was a significant increase in percentage of SNOM [19]. This was in line with our trend where SNOM was adopted in $34 \%$ of our patients and similar to $39.5 \%$ in Bertrand, et al., in 2003 [11], but even higher than reported in the literature, 3.5\% [17] and 6.8\% [10].

\subsection{Operative Management}

Operative treatment was adopted in $66 \%$ of our patients. Other studies were in the range of $46 \%$ - 59.9\% [12,14, 15,17]. Total splenectomy $61.7 \%$ was the commonest operation performed in our splenic injured patients. In the literature the rate range was $32 \%-72 \%[10,12,14$, $15,20]$. Whereas Splenorrhaphy was practiced in $4.3 \%$ of our patients and this simulate others' findings [20,21], but lower than $19.2 \%$ in a Nigerian study [10]. None of our patients underwent partial splenectomy neither splenic artery embolization. The latter modality of treatment was not practiced in our setting due to lack of ex- pertise personnel.

\subsection{Outcome}

Uneventful discharge was seen in $93.6 \%$ of our patient compared to $86.3 \%$ in other study [10]. Three patients died, making a mortality of $6.4 \%$ in our study. This overall mortality is comparable to $3.8 \%$ [13]. However, it was lower than 10.9\% [12] and 19\% [15] in other studies.

Our study has some limitations. The major limitations are, no unified guideline was used in the hospitals regarding patients with splenic injuries, second FAST was not adopted universally in abdominal trauma patients, third the decision to operate was based on clinical judgment, fourth surgical registrar were not trained in the methods of splenic salvage fifth interventional radiologist were not available for selective splenic artery embolization in minor grade of splenic injuries

\section{Conclusion}

In conclusion, splenic injuries in our study usually follow blunt abdominal trauma, particularly after road traffic accidents. It is common during the first four decades of life with males being frequently affected. The outcome is excellent and the great success rate of adopting selective non-operative management is worthwhile in all hospitals.

\section{REFERENCES}

[1] B. Schnüriger, J. Kilz, D. Inderbitzin, M. Schafer, R. Kickuth, M. Luginbühl, et al., "The Accuracy of FAST in Relation to Grade of Solid Organ Injuries: A Retrospective Analysis of 226 Trauma Patients with Liver or Splenic Lesion,” BMC Medical Imaging, Vol. 9, 2009, p. 3. http://dx.doi.org/10.1186/1471-2342-9-3

[2] S. R. Klepac, “Spleen Trauma Imaging,” 2011. http://emedicine.medscape.com/article/373694-overview

[3] H. L. Pachter and J. Grau, "The Current Status of Splenic Preservation,” Advances in Surgery, Vol. 4, No. 34, 2003, pp. 137-174.

[4] S. Di Saverio, E. E. Moore, G. Tugnoli, N. Naidoo, L. Ansaloni, S. Bonilauri, et al., "Non Operative Management of Liver and Spleen Traumatic Injuries: A Giant with Clay Feet," World Journal of Emergency Surgery, Vol. 7, No. 3, 2012, pp. 1-4. http://dx.doi.org/10.1186/1749-7922-7-3

[5] C. H. van der Vliesm, O. M. van Delden, B. J. Punt, K. J. Ponsenm, J. A. Reekers and J. C. Goslings, "Literature Review of the Role of Ultrasound, Computed Tomography and Transcatheter Arterial Embolization for the Treatment of Traumatic Splenic Injuries,” CardioVascular and Interventional Radiology, Vol. 33, 2010, pp. 1079-1087. http://dx.doi.org/10.1007/s00270-010-9943-6

[6] J. M. Haan, G. V. Bochicchio, N. Kramer and T. M. Scalea, "Nonoperative Management of Blunt Splenic Injury: A 5-Year Experience,” The Journal of Trauma In- 
jury, Infection, and Critical Care, Vol. 58, 2005, pp 492498. http://dx.doi.org/10.1097/01.TA.0000154575.49388.74

[7] S. Abunnaja, L. Panait, J. A. Palesty and S. Macaron, "Laparoscopic Splenectomy for Traumatic Splenic Injury after Screening Colonoscopy," Case Reports in Gastroenterology, Vol. 6, 2012, pp. 624-628. http://dx.doi.org/10.1159/000343428

[8] S. A. Rehim, H. Dagash, P. P. Godbole, A. A. Raghavan and G. V. Murthi, "Subtle Radiological Features of Splenic Avulsion Following Abdominal Trauma," Case Reports in Medicine, Vol. 2010, 2010, pp. 1-4. http://dx.doi.org/10.1155/2010/762493

[9] D. S. P. Popovic and M. Jeromel, "Percutaneous Transcatheter Arterial Embolization in Haemodynamically Stable Patients with Blunt Splenic Injury,” Radiology and Oncology, Vol. 44, No. 1, 2010, pp. 30-33. http://dx.doi.org/10.2478/v10019-010-0011-2

[10] E. A. Agbakwuru, A. A. Akinkuolie, O. A. Sowande, O. A. Adisa, O. I. Alatise, U. U. Onakpoya, O. Uhumwango and A. R. K. Adesukanmi, "Splenic Injuries in a Semi Urban Hospital in Nigeria," East and Central African Journal of Surgery, Vol. 13, No. 1, 2008, pp. 95-100.

[11] B. Bessoud, A. Denys, J.-M. Calmes, D. Madoff, S. Qanadli and P. Schnyder, "Nonoperative Management of Traumatic Splenic Injuries: Is There a Role for Proximal Splenic Artery Embolization?” AJR, Vol. 186, No. 3, 2006, pp. 779-785. http://dx.doi.org/10.2214/AJR.04.1800

[12] S. Sinha, S. V. V. Raja and M. H. Lewis, "Recent Changes in the Management of Blunt Splenic Injury: Effect on Splenic Trauma Patients and Hospital Implications," Annals of The Royal College of Surgeons of England, Vol. 90, No. 2, 2008, pp. 109-112. http://dx.doi.org/10.1308/003588408X242033

[13] J. A. Weinberg, L. J. Magnotti, M. A. Croce and N. M. Edwards, "The Utility of Serial Computed Tomography Imaging of Blunt Splenic Injury: Still Worth a Second Look?” The Journal of Trauma Injury, Infection, and Critical Care, Vol. 62, No. 5, 2007, pp. 1143-1148.
http://dx.doi.org/10.1097/TA.0b013e318047b7c2

[14] A. A. Akinkuolie, O. O. Lawal, O. A. Arowolo, E. A. Agbakwuru and A. R. K. Adesunkanmi, "Determinants of Splenectomy in Splenic Injuries Following Blunt Abdominal Trauma,” SAJS, Vol. 48, No. 1, 2010, pp. 15-19.

[15] T. C. König, N. R. M. Tai and M. S. Walsh, "Blunt Splenic Trauma," Annals of The Royal College of Surgeons of England, Vol. 90, No. 7, 2008, pp. 626-627. http://dx.doi.org/10.1308/003588408X321602

[16] J. J. Hallman, K. J. Brasel, N. Yoganandan and F. A. Pintar, "Splenic Trauma as an Adverse Effect of TorsoProtecting Side Airbags: Biomechanical and Case Evidence," Annals of Advances in Automotive Medicine, Vol. 53, 2009, pp. 13-24.

[17] D. Demetriades, P. Hadjizacharia, C. Constantinou, C. Brown, K. Inaba, P. Rhee and A. Salim, "Selective Nonoperative Management of Penetrating Abdominal Solid Organ Injuries,” Annals of Surgery, Vol. 244, No. 4, 2006, pp. 620-628.

http://dx.doi.org/10.1097/01.sla.0000237743.22633.01

[18] C. C. Burlew, L. Z. Kornblith, E. E. Moore, J. L. Johnson and W. L. Biffl, "Blunt Trauma Induced Splenic Blushes Are Not Created Equal," World Journal of Emergency Surgery, Vol. 7, No. 1, 2012, p. 8. http://dx.doi.org/10.1186/1749-7922-7-8

[19] M. Hurtuk, R. L. Reed, T. J. Esposito, K. A. Davis and F. A. Luchette, "Trauma Surgeons Practice What They Preach: The NTDB Story on Solid Organ Injury Management,” Journal of Trauma, Vol. 61, No. 2, 2006, pp. 243-254.

[20] A. Mikocka-Walus, H. C. Beevor, B. Gabbe, R. L. Gruen, J. Winnett and P. Cameron, "Management of Spleen Injuries: The Current Profile,” ANZ Journal of Surgery, Vol. 80, No. 3, 2010, pp. 157-161. http://dx.doi.org/10.1111/j.1445-2197.2010.05209.x

[21] S. R. Todd, M. Arthur, C. Newgard, J. R. Hedges and R. J. Mullins, "Hospital Factors Associated with Splenectomy for Splenic Injury: A National Perspective,” Journal of Trauma, Vol. 57, 2004, pp. 1065-1071.

\author{
Abbreviations \\ DPL: Diagnostic peritoneal lavage, \\ FAST: Focused Abdominal Sonography for Trauma, \\ HDU: High Dependency Unit, \\ OPSS: Over-whelming post splenectomy sepsis, \\ SNOM: Selective non-operative management.
}

